\title{
Experimental Research on the Dynamic Lubricating Performance of Slipper/Swash Plate Interface in Axial Piston Pumps
}

\author{
Junjie Zhou* ${ }^{*}$, Jichen Zhou and Chongbo Jing
}

\begin{abstract}
The interface between the slipper/swash plate is one of the most important frication pairs in axial piston pumps. The test of this interface in a real pump is very challenging. In this paper, a novel pump prototype is designed and a test rig is set up to study the dynamic lubricating performance of the slipper/swash-plate interface in axial piston machines. Such an experimental setup can simulate the operating condition of a real axial piston pump without changing the relative motion relationship of the interfaces. Considering the lubricant oil film thickness as the main measurement parameter, the attitude of the slipper under the conditions of different load pressure, rotation speed and charge pressure are studied experimentally. After the test, the wear state of the swash plate is observed. According to the friction trace on the surface of the swash plate, the prediction for the attitude of the slipper and the zone easy to wear are verified.
\end{abstract}

Keywords: Slipper, Axial piston pump, Experimental study, Oil film thickness

\section{Introduction}

The axial piston machines are essential components in fluid power community, which are widely used in industry due to its high reliability, power density and competitive efficiencies [1,2]. There are 3 significant interfaces in such a machine including the slipper/swash-plate interface, the piston/cylinder interface and the cylinder/valve plate interface. Between the three interfaces, the slipper/ swash-plate interface is the most complicated [3] not only because the pump kinetics but also because the delicate micro motions including the tilting $[4,5]$, squeezing [6] and spinning $[7,8]$ of the slipper. In recent years, with the development of simulation model and commercial software, the theoretical research on the lubrication of the slipper/swash plate interface has been comprehensive and thorough, expanding from static to dynamic [9], steady state to unsteady state [10,11], single-factor to multi-factor coupling $[12,13]$. Most recently, several

*Correspondence: bit_zhou50082@163.com

School of Mechanical Engineering, Beijing Institute of Technology, Beijing 100081, China fully coupled fluid-structure-thermal models have also been proposed, such as Ref. [14] studied the multi-body dynamics considering the mixed lubrication model, Ref. [15] presented a transient thermoelastohydrodynamic lubrication model and Ref. [16] predicted the slipper behaviors use a similar advanced model.

At the same time, many researchers devote themselves to the experimental research; focus on the lubricating performance of the key interfaces. Only by the test in real condition to verify the accuracy of the theoretical models, can the study on its lubricating performance truly progress. The experimental study on the slipper/swashplate interface also experiences the evolution from static to dynamic [17], from steady to unsteady [18], from indirect to direct measurement [19], from model test to real pump test [20, 21]. Chao et al. [3] presented a review of the test rigs of the slipper bearing in axial piston pump. The test rigs are classified into four groups in this paper: stationary cylinder and swash plate [22], stationary cylinder and rotational swash plate without tilt [23, 24], stationary cylinder and rotational swash plate with tilt [25] 
and stationary swash plate and rotational cylinder $[26$, 27].

It can be known from the literature that the test on the dynamic lubricating performance of the slipper/swash plate interface is still in developing [3, 28], and most research is based on static lubrication [29] or the test rig with single piston [30] in a modified prototype instead of a real pump. Therefore, the real-time measurement of the real pump is less carried out, resulting in that the actual lubricating state of slipper/swash plate interface in piston pump still cannot be accurately acquired.

In this paper, a test rig for dynamic lubricating state of slipper/swash plate interface in a real pump is set up, and the test is performed under the conditions of different load pressure, rotation speed and charge pressure comprehensively, taking the oil film thickness as the main measurement parameter. From the 3-points of the oil film thickness, the attitude of slipper can be decided, therefore the micro-motion dynamics of the slipper and contacting on the swash plate will also be known. The future work of this paper could be to verify the simulation model by using the test results and to optimize the design of the slipper interface.

\section{Experimental Setup}

\subsection{Description of Test Rig}

From the previous studies, it is possible to find many test rigs in terms of the axial piston pumps. However, due to the limitation of test difficulty and sensor layout, most of the test pumps only include one certain part of the machine, resulting in that the test pump cannot entirely represent the real operating state of the machine.

For this reason, a transparent test pump was particularly designed and manufactured. Figure 1 shows the main structure of this test prototype. The test pump was

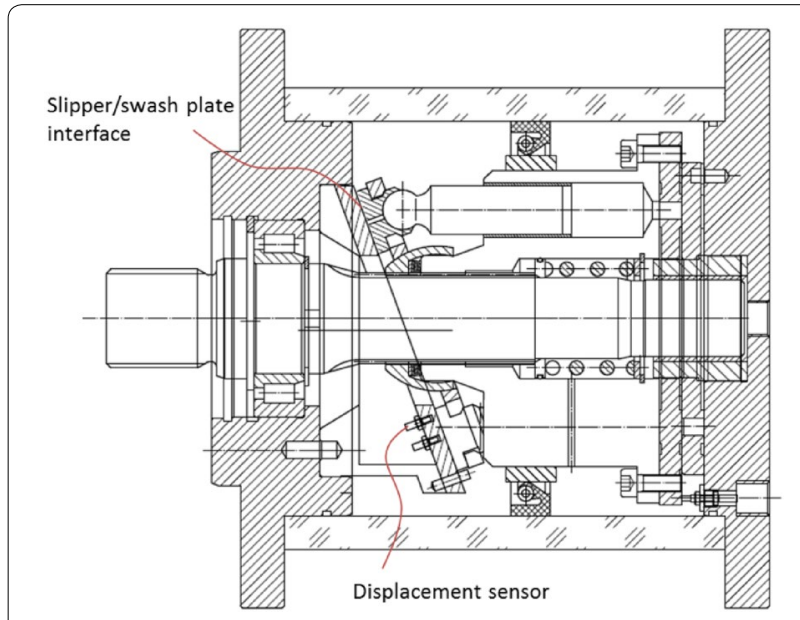

Figure 1 Structure of the test pump re-designed based on a commercial pump. The pistons, slippers and cylinder are taken from the original pump, but the swash plate, valve plate and housing are carefully devised in order to mount the micro displacement sensors (as shown in Figure 1), which are adopted to measure the oil film thickness of the sliding interfaces. The pump housing is made of PMMA for the convenience of observing the flow field inside the pump.

It should be emphasized that the test pump is very close to a real commercial pump, because the motion of all the components including the pistons, slippers and cylinder is unchanged. Therefore the original operating condition can be simulated to the max. As shown in Figure 2, the test rig mainly consists of the following parts: the driving motor and its control unit, the speed and torque sensor, the test pump, the auxiliary hydraulic system and the data collection module. The photo of the real test rig is shown in Figure 3.

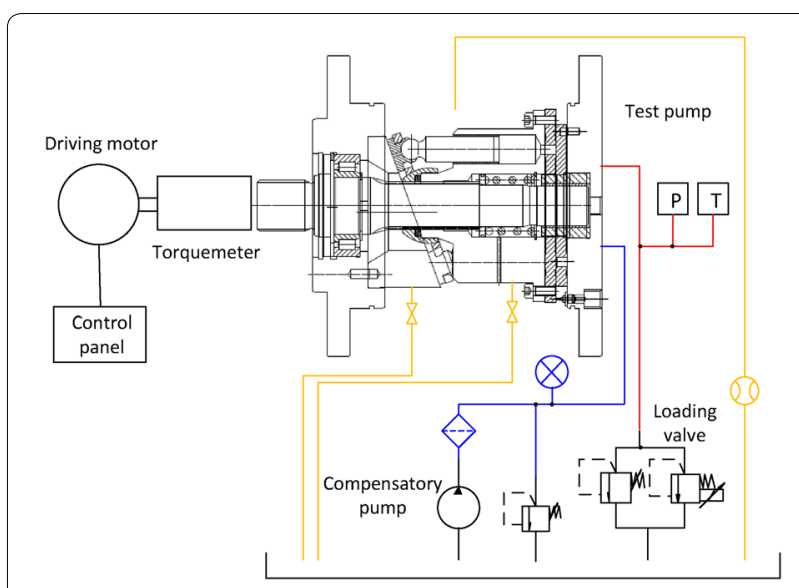

Figure 2 Schematic of the test system

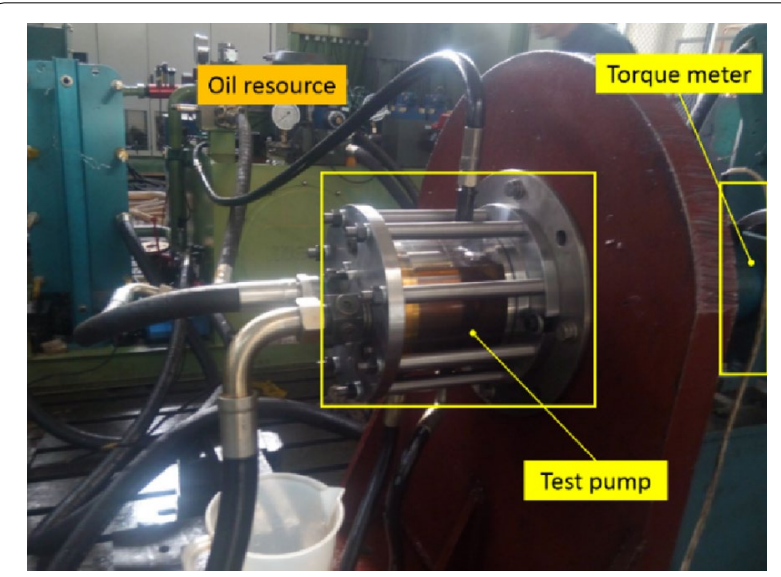

Figure 3 Photo of the test system 


\subsection{Sensor Mounting}

Oil film test system is the core of the test rig for dynamic lubricating state of the slipper/swash-plate interface. Considering the functional expectation and practical feasibility, the sensors were fixed on the immovable swash-plate. In this way, it is necessary to design many mounting holes on the swash-plate, in the moving track of slipper for the purpose of making up the lack of not continuous measurement of the film thickness. At least three sensors should be put at each measuring position to determine the distribution of oil film thickness and the posture of slipper, according to the basic principle that three non-collinear points can define a plane. In addition, temperature sensors need to be added to the test system to monitor the oil temperature.

As shown in Figure 4, in the $o-x y z$ coordinate system, A1, A2 and A3 are three points on the exterior margin of the slipper, and their interval angles are all $2 \pi / 3$. Let $h_{1}, h_{2}$ and $h_{3}$ be the actual oil film thickness of A1, A2 and $\mathrm{A} 3$, respectively.

Let $R_{\text {out }}$ be the radius of A, B and C on the slipper. Let $\alpha, \varphi$ and $h_{0}$ be the incline angle, the azimuth angle and the central oil film thickness of the slipper, respectively. When these three parameters are confirmed, $h_{1}, h_{2}$ and $h_{3}$ can be obtained by Eq. (1):
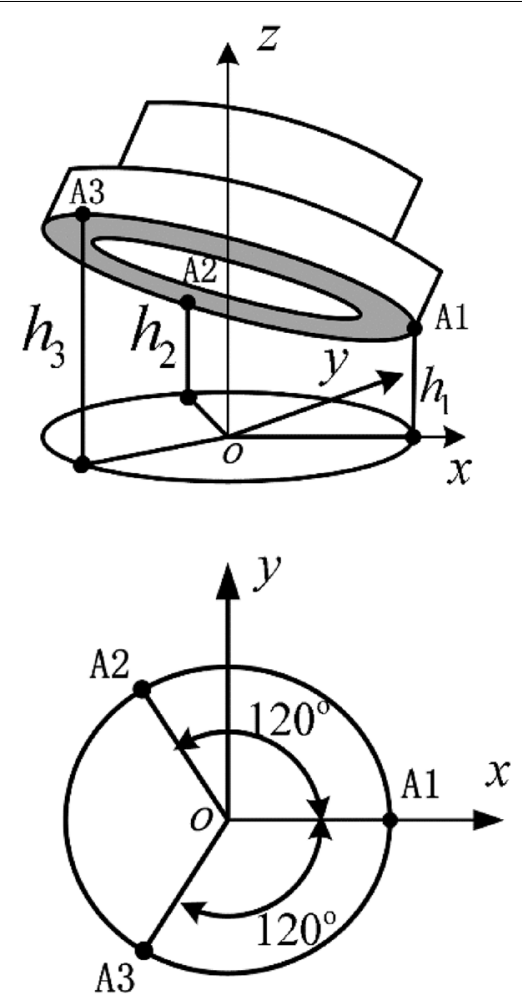

Figure 4 Description method of the 3-point film thickness

$$
\begin{aligned}
& h_{1}=h_{0}+R_{\text {out }} \alpha \cos (-\varphi), \\
& h_{2}=h_{0}+R_{\text {out }} \alpha \cos \left(\frac{2 \pi}{3}-\varphi\right), \\
& h_{3}=h_{0}+R_{\text {out }} \alpha \cos \left(\frac{4 \pi}{3}-\varphi\right) .
\end{aligned}
$$

When $h_{1}, h_{2}$ and $h_{3}$ are known, expand the cosine function in Eq. (1) and compare it with Eq. (2), $\alpha, \varphi$ and $h_{0}$ can be obtained as follows:

$$
\begin{aligned}
& h_{0}=\frac{h_{1}+h_{2}+h_{3}}{3}, \\
& \alpha=\sqrt{\frac{\left(h_{2}-h_{3}\right)^{2}}{3 R_{\text {out }}^{2}}+\frac{\left(2 h_{1}-h_{2}-h_{3}\right)^{2}}{9 R_{\text {out }}^{2}},} \\
& \sin \varphi=\frac{h_{2}-h_{3}}{\sqrt{3} R_{\text {out }} \alpha}, \\
& \cos \varphi=\frac{2 h_{1}-h_{2}-h_{3}}{3 R_{\text {out }} \alpha} .
\end{aligned}
$$

The electric eddy current displacement sensor is used in the test system mainly to measure the micron oil film thickness with high accuracy. The sensor has the features of high precision, high resolution and high test bandwidth because of the principle of electric eddy current effect. In order to ensure the accuracy, the scope diameter detected by the sensor probe is at least three times of the probe diameter.

Two kinds of layout schemes of the mounting holes for sensors on the slipper are designed in the test, as shown in Figures 5 and 6 . On the one hand, the bottom dead center (BDC) in slipper's moving track is selected as a detection point for oil film thickness. Because the bottom dead center (BDC) and the top dead center (TDC) on the slipper lie in the conversion area from high pressure to low pressure, hence the oil film thickness and the overturning condition of the slipper in this area is changing drastically, so the TDC is chosen as the detection point.

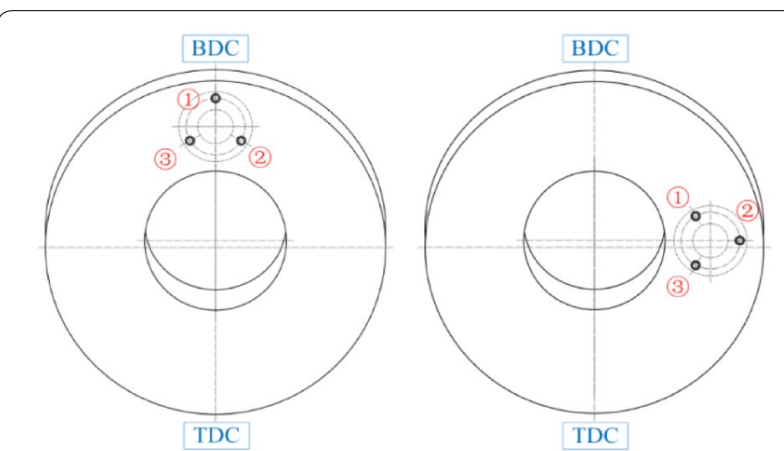

Figure 5 Two kinds of layout schemes of sensor mounting at the swash plate 

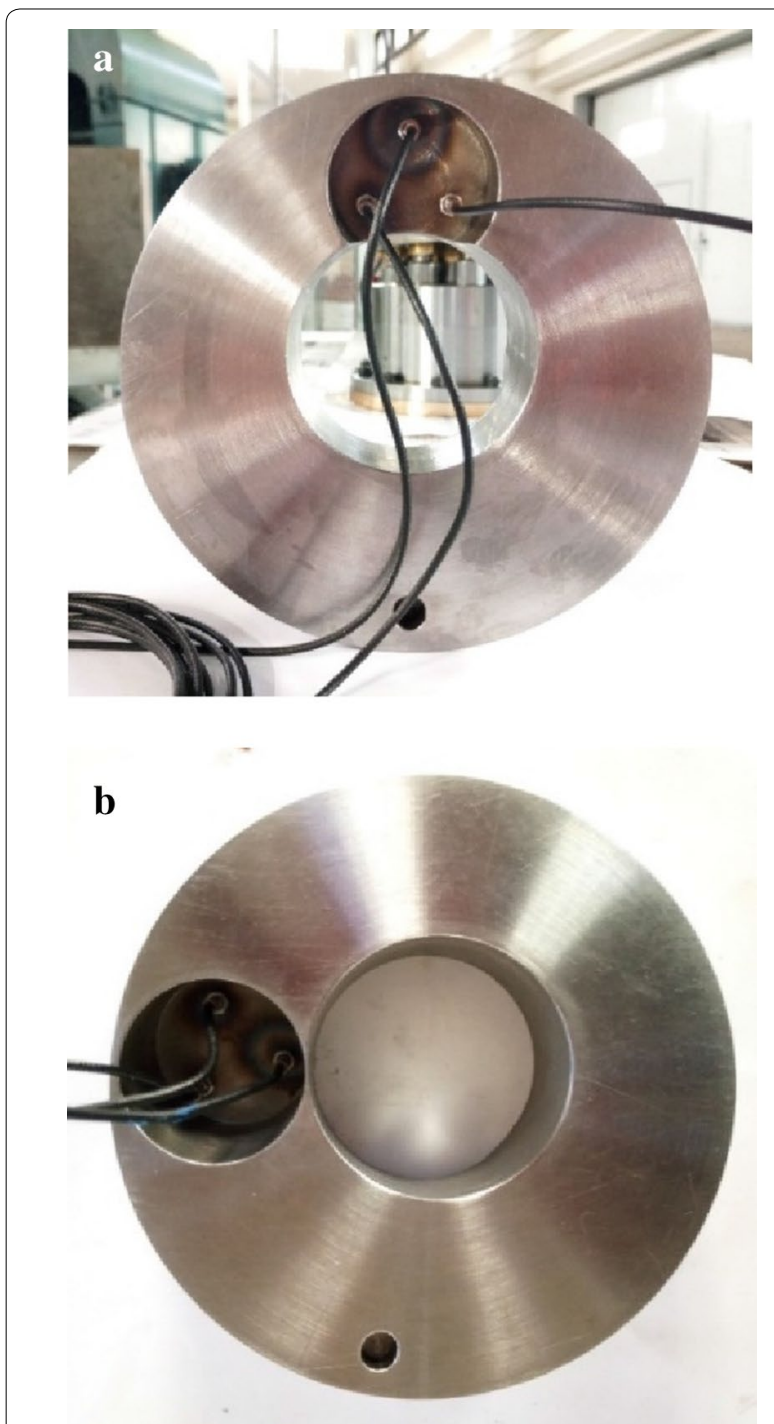

Figure 6 Photo of sensor mounting: (a) at TDC; (b) at the high or low pressure zone

On the other hand, the dynamic lubricating condition in the high and low pressure areas of the slipper is also extremely notable. So sensors are put in the middle of the right half of slipper's moving track (facing to the friction surface of the swash-plate). When the line shaft rotates clockwise, the oil film thickness in the high pressure area is measured, while when the line shaft rotates anti-clockwise, the film thickness in the low pressure area is measured. The test pump is designed completely symmetrically in the left and right directions, so only the high and low pressure pipes need to be replaced before the rotation of high and low pressure.

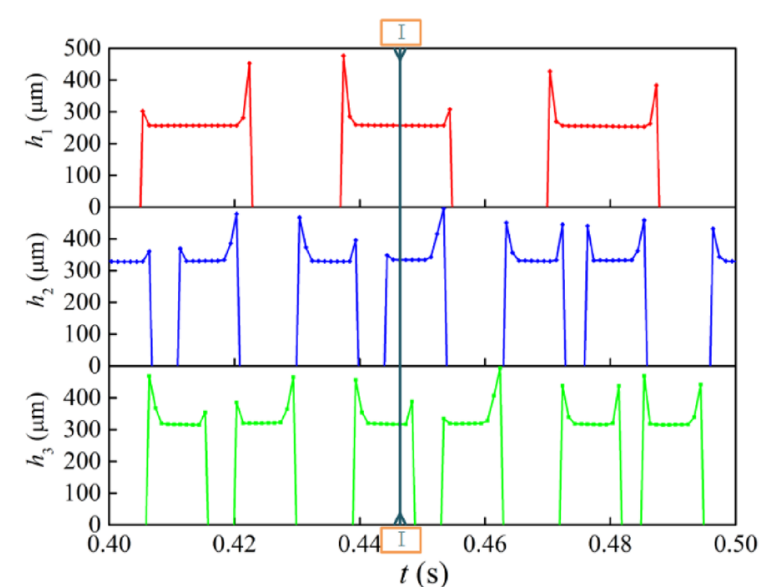

Figure 7 Oscillogram of data collected online

Therefore, the swash plate in Figure 6(a) is used to perform the conversion region test and the one in Figure 6(b) is used to perform the low and high pressure region test.

\section{Result Analysis \\ 3.1 Test Data}

The oscillogram of data collected is shown in Figure 7 when the rotation speed of the piston pump is $200 \mathrm{r} / \mathrm{min}$. $h_{1}, h_{2}, h_{3}$ are the real-time data measured by No. 1 sensor, No. 2 sensor and No. 3 sensor, respectively. On this basis, the actual oil film thickness can be obtained by subtracting the benchmark values confirmed during calibration process. It is not difficult to find from Figure 7 that the No. 1 sensor detects the sealing belt once per shaft revolution, and the No. 2 and No. 3 sensor detect it twice per shaft revolution, which is determined by the position of the sensors, no matter which mounting model shown in Figure 6.

\subsection{High Pressure Region}

Figure 8 shows the change of oil film thickness with the load pressure when the rotating speed is $1000 \mathrm{r} / \mathrm{min}$. It can be seen from the curve that the measurement results of the 3 sensors decreases gradually with the increase of pressure, and the oil film thickness measured by No. 1 sensor is almost the minimum all the time of the three sensors, which indicates that the posture of the slipper in this position basically is "head up", and the convergent gap is forming. Moreover, the oil film thickness decreases with the increase of pressure, and the overturning angle decreases with the increase of pressure.

Figure 9 shows the change of the oil film thickness with the rotation speed at pressure of 60 bar. It can be seen from the curve that the measurement of No. 1 sensor is almost the minimum all the time of the 3 sensors. 


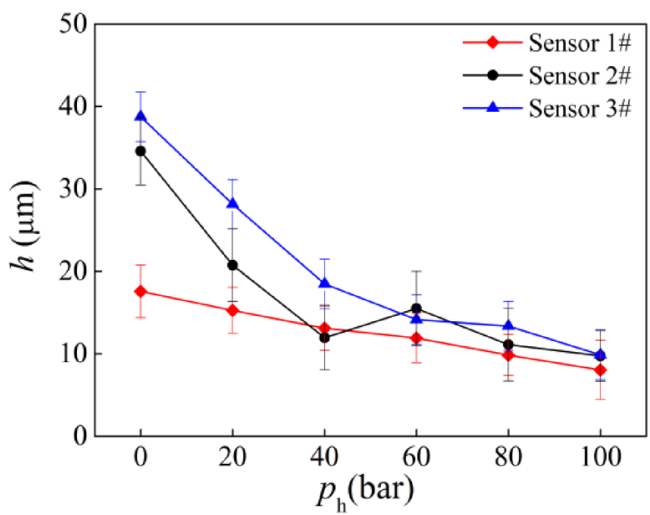

Figure 8 Change of the oil film thickness with pressure at high pressure region

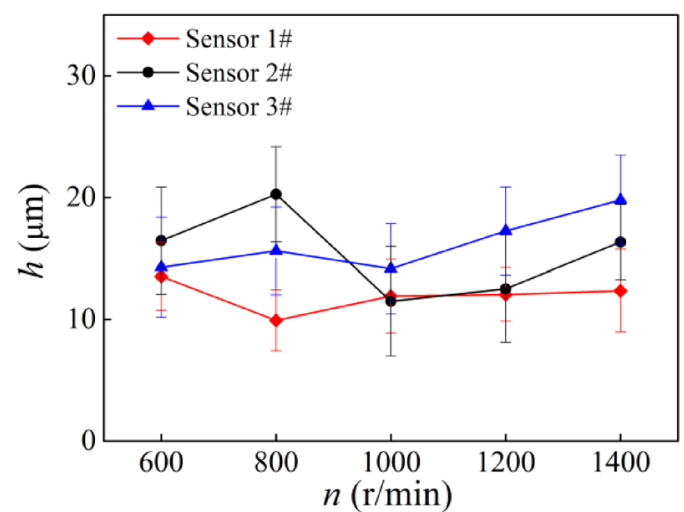

Figure 9 Change of the oil film thickness with the rotation speed at high pressure region

According to the position of the sensor, it is concluded that the slipper is almost inclining to the line shaft all the time, the oil film thickness increases with the increase of rotation speed (except No. 2), and the slipper overturn intensifies.

\subsection{Low Pressure Region}

After the test in high pressure region, the inlet and outlet pipelines are exchanged and the running of the driving motor are changed from clockwise to anti-clockwise, then what the sensor measures is the oil film thickness in the low pressure region. The charge pressure is 20 bar and the rotation speed of the driving motor rises from 200 to $1400 \mathrm{r} / \mathrm{min}$. The results are shown in Figure 10.

It can be seen from the figure that the measured oil film thickness of No. 1 sensor is basically less than that of No. 2 sensor and No. 3 sensor with the increase of rotation speed, which indicates that the slipper is inclining to No. 1 sensor, that is, overturn to the line shaft. In addition, the difference between No. 2/No. 3 sensor

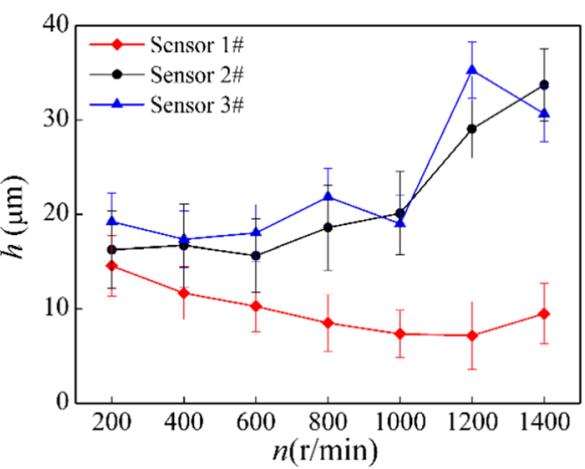

Figure 10 Change of the oil film thickness with the rotation speed at low pressure region

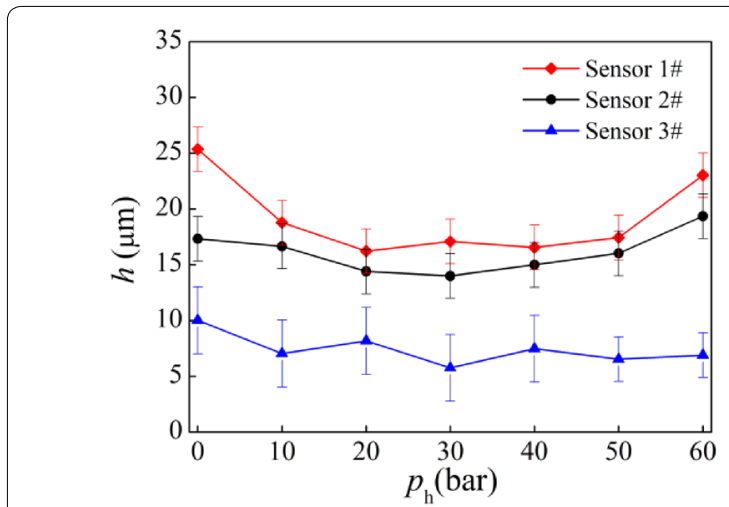

Figure 11 Change of the oil film thickness with the pressure at the conversion region from high pressure to low pressure

and No. 1 sensor in Figure 10 is getting bigger, because when increasing the speed, the linear velocity (the slipper relative to the swash-plate) in the outer edge of trajectory is larger than that in the inner edge, so the dynamic pressure effect of the slipper in the outer edge is more remarkable, which increases the support force at the slipper, the imbalance of the oil support force at the bottom of the slipper increases, and the overturn becomes more serious.

\subsection{Conversion Region from High Pressure to Low Pressure} The measured oil film thickness is shown in Figure 11 when the rotation speed of the driving motor is $600 \mathrm{r} /$ min and the pressure rises from 0 to 60 bar. The curve shows the oil film thickness at sensor No. 3 is almost the smallest of the 3 sensors all the time, which indicates that the posture of the slipper is "head up", the convergent gap is forming, and it's conducive to the generation of the dynamic pressure effect. 


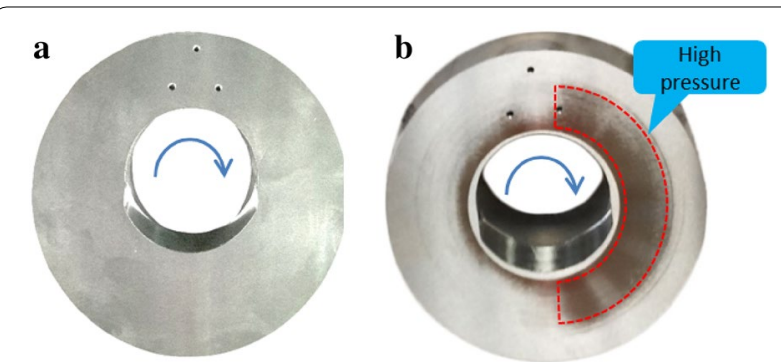

Figure 12 Comparisons of friction conditions on the swash-plate before and after the test: $\mathbf{a}$ before the test; $\mathbf{b}$ after the test

\subsection{Wear Observation}

After the test of oil film thickness, the swash-plate was taken out and compared with that before the test, and obvious friction trace was found on the surface of swash-plate, as shown in Figure 12. It can be seen from the figure that the trace color in high pressure region is deeper than that in low pressure region and the solid contact in the inner edge of the slipper trajectory is more serious than that in the outer edge, which validates that the slipper overturns towards the shaft in the high pressure region. Similarly, according to the appearance in the low pressure region, it can be clearly found that the slipper overturns towards the shaft.

\section{Conclusions}

(1) Taking the attitude of the slipper as the main test target, the rig testing dynamic lubricating performance is designed, which realizes the dynamic posture measurement of the slipper/swash plate pair under the actual working condition.

(2) The test results show that: In high pressure area, the gap between slipper and swash-plate is convergent, the slipper posture is "head up", and the inclination angle of slipper is smaller. In low pressure area, the oil film thickness is thicker, the inclination angle of slipper is larger and the gap is divergent in the latter half stage.

(3) The effective test scheme provided in this paper is very close to the actual situation and works credibly, which has a guiding significance for the future study of dynamic lubrication of the slipper/swashplate interface.

\section{Acknowledgements}

The authors would like to acknowledge the financial support from the Open Foundation of the State Key Laboratory of Fluid Power and Mechatronic Systems.

\section{Authors' Contributions}

J-CZ contributed the experimental work, including the built of test system and measurement and data analysis. J-JZ contributed the theoretical work and wrote the paper. CJ contributed the revise of this paper. All authors read and approved the final manuscript.

\section{Authors' Information}

Junjie Zhou is currently an associate professor at Beijing Institute of Technology, China, visiting scholar of Maha Fluid Power Center of Purdue University, USA. His research interests include fluid power systems, soft robotics and micro hydraulic systems.

Jichen Zhou is currently a master candidate at Beijing Institute of Technology, China.

Chongbo Jing is currently an associate professor at Beijing Institute of Technology, China.

\section{Funding}

Supported by Open Foundation of the State Key Laboratory of Fluid Power and Mechatronic Systems (Grant No. 201718).

\section{Competing Interests}

The authors declare that they have no conflict of interest.

Received: 26 March 2019 Revised: 28 December 2019 Accepted: 20 February 2020

Published online: 06 March 2020

\section{References}

[1] HYYang, M Pan. Engineering research in fluid power: a review. J. Zhejiang Univ. Sci. A, 2015, 16(6): 427-442.

[2] G Mohn, T Nafz, Swash plate pumps-the key to the future. 10th International Fluid Power Conference, Dresden, Germany, 8-10, March, 2016.

[3] Q Chao, J H Zhang, B Xu, et al. Test rigs and experimental studies of the slipper bearing in axial piston pumps: A review. Measurement, 2019, 132: 135-149.

[4] S Lin, J B Hu. Tribo-dynamic model of slipper bearings. Appl. Math. Model., 2015, 39(2): 548-558.

[5] H S Tang, Y B Yin, J Li. Lubrication characteristics analysis of slipper bearing in axial piston pump considering thermal effect. Lubr. Sci., 2016, 28(2): 107-124.

[6] U Wieczorek, M Ivantysynova. Computer aided optimization of bearing and sealing gaps in hydrostatic machines - The simulation tool Caspar. International Journal of Fluid Power, 2002, 3(1): 7-20.

[7] J H Zhang, Q Chao, Q N Wang, et al. Experimental investigations of the slipper spin in an axial piston pump. Measurement, 2017, 102: 112-120.

[8] C B Jing, J J Zhou, J C Zhou. Experimental study of churning losses in swash plate axial piston pump. Journal of Beijing Institute of Technology, 2019, 28(03): 529-535.

[9] M Pelosi, M Ivantysynova. A new fluid-structure interaction model for the slipper-swash plate interface. Proc. of 5 th Fluid Power Net International PhD Symposium, Cracow, Poland, 2008.

[10] R M Harris, K A Edge, D G Tilley. Predicting the behavior of slipper pads in swashplate-type axial piston pumps. Journal of Dynamic Systems Measurement and Control-Transactions of the ASME, 1996, 118(1): 41-47.

[11] J M Bergada, S Kumar, D L Davies, et al. A complete analysis of axial piston pump leakage and output flow ripples. Appl. Math. Model, 2012, 36(4): 1731-1751.

[12] R Ivantysyn, J Weber. "Transparent pump"-an approach to visualize lifetime limiting factors in axial piston pumps. 9th FPNI Ph. D. Symposium on Fluid Power, Florianópolis, SC, Brazil, 26-28 October, 2016.

[13] J C Zhou, J J Zhou, C B Jing. Dynamic characteristics of lubrication and wear prediction of slipper/swash-plate in axial piston pumps. Journal of Beijing Institute of Technology, 2019, 28(3): 519-528.

[14] S Hashemi, A Kroker, L Bobach, et al. Multibody dynamics of pivot slipper pad thrust bearing in axial piston machines incorporating thermal elastohydrodynamics and mixed lubrication model. Tribol. Int., 2016, 96: 57-76. 
[15] A Schenk, M Ivantysynova. A transient thermoelastohydrodynamic lubrication model for the slipper/swashplate in axial piston machines. J. Tribol. 2015, 137(3): 031701.

[16] H S Tang, Y Ren, J W Xiang. A novel model for predicting thermoelastohydrodynamic lubrication characteristics of slipper pair in axial piston pump. Int. J. Mech. Sci., 2017, 124: 109-121.

[17] E Koc, C J Hooke. Considerations in the design of partially hydrostatic slipper bearings. Tribology International, 1997, 30(11): 815-823.

[18] X Wang, A Yamaguchi. Characteristics of hydrostatic bearing/seal parts for water hydraulic pumps and motors. Part 1: experiment and theory. Tribol. Int., 2002, 35(7): 425-433.

[19] N D Manring, C L Wray, Z L Dong. Experimental studies on the performance of slipper bearings within axial-piston pumps. Journal of TribologyTransactions of the ASME, 2004, 126(3): 511-518.

[20] F Canbulut, C Sinanoglu, E Koc. Experimental analysis of frictional power loss of hydrostatic slipper bearings. Industrial Lubricating and Tribology, 2009, 61(2-3): 123-131.

[21] N Iboshi, A Yamaguchi. Characteristics of a slipper bearing for swash plate type axial piston pumps and motors: 4th Report, effects of surface roughness. Bulletin of the JSME, 2008, 26(219): 1583-1589.

[22] N D Manring, C L Wray, Z L Dong. Experimental studies on the performance of slipper bearings within axial-piston pumps. J. Tribol., 2004, 126 (3): 511-518.
[23] F Canbulut, E Koc, C Sinanog lu, Design of artificial neural networks for slipper analysis of axial piston pumps. Ind. Lubr. Tribol., 2009, 61 (2): 67-77.

[24] E Yilmaz, C Sinanog $\%$ lu, ES Topal. Experimental analyses of the effects of slipper bearing geometry and working conditions on the system load carrying capacity in axial piston pumps. J. Balk. Tribol. Assoc., 2014, 20(2): 247-258.

[25] T Kazama, M Suzuki, K Suzuki. Relation between sliding-part temperature and clearance shape of a slipper in swashplate axial piston motors. JFPS Int. J. Fluid Power Syst., 2014(1): 10-17.

[26] J H Zhang, Q Chao, B Xu, et al. Novel three-piston pump design for a slipper test rig. Appl. Math. Model, 2017, 52: 65-81.

[27] Q Chao, J H Zhang, B Xu, et al. Multi-position measurement of oil film thickness within the slipper bearing in axial piston pumps. Measurement, 2018, 122: 66-72.

[28] A Schenk. Predicting lubrication performance between the slipper and swashplate in axial piston hydraulic machines. Purdue University, 2014.

[29] Q Ai, H Zhou, Z Zhang, et al. Development of lubricating characteristics testing system of friction pair in axial piston pump. Hydraulics and Pneumatics, 2004, 11: 22-25.

[30] N A Spencer. Design and development of a novel test method to measure the slipper/swashplate interface fluid film in a positive displacement machine. Purdue University, 2014

\section{Submit your manuscript to a SpringerOpen ${ }^{\odot}$ journal and benefit from:}

- Convenient online submission

- Rigorous peer review

- Open access: articles freely available online

- High visibility within the field

- Retaining the copyright to your article

Submit your next manuscript at $>$ springeropen.com 